\title{
Apresentação do Projeto de extensão universitária "Fortalecimento das Capacidades das Educadoras do Programa CAIF no estado de Cerro Largo-Uruguai"
}

\author{
Presentación del Proyecto de extensión universitaria \\ "Fortalecimiento de las Capacidades de las Educadoras de Plan CAIF \\ Cerro Largo"
}

\author{
Mariana Porta Galván ${ }^{1}$; Maria Bentancor ${ }^{1}$; Yandira Álvarez ${ }^{1}$ \\ ${ }^{1}$ mportagalvan@gmail.com, Centro de Estudios de la Frontera - UdelaR.
}

\begin{abstract}
Resumen
Dentro de la línea de investigación Estado, políticas sociales y ciudadanía en frontera, es relevante conocer la realidad de las políticas sociales orientadas a la primera infancia y sus implementaciones. Esta ponencia presenta un proyecto de extensión universitaria realizada con los centros CAIF de Cerro Largo con el propósito de fortalecer las prácticas de los operadores sociales de estos centros, a partir de las siguientes preguntas: ¿Qué características asume la implementación de esta política pública en un departamento fronterizo? ¿Qué desafíos plantea a sus operadores? Consideramos que la implementación de una política social, más allá de la forma en que se concibe, diseña y expresa en sus documentos, implica un proceso de apropiación que conlleva interpretaciones y adaptaciones que se manifiestan en prácticas. Estas, a su vez, responden a disposiciones, hábitos y saberes (entendidos como conocimientos tácitos y explícitos) de los operadores involucrados, en un vínculo directo con la cultura propia de los contextos en los que se desarrollan. En ese proceso de implementación y sus múltiples niveles de gestión, se encuentran los desafíos a los cuales pretendemos aportar desde una propuesta de capacitación de operadores, que responda a la diversidad de cada territorio y de cada contexto social.
\end{abstract}

Palabras clave: capacitación, extensión universitaria, frontera, políticas sociales hacia la infancia y la familia, vulnerabilidad

\section{Introducción}

Este proyecto se enmarca dentro del programa de actividades de extensión universitaria del Centro de Estudios de la Frontera de la Casa de la Universidad en Cerro Largo. Su elección responde a dos motivos: Desde la elaboración del plan estratégico para la Casa de la Universidad de Cerro Largo, CUCEL 2015 se prioriza, como uno de los ejes, las poblaciones vulnerables y el Sistema de Cuidados. Desde el Centro de Estudios de la Frontera (CEF), dentro de la línea de investigación Estado, políticas sociales y ciudadanía en frontera, es relevante conocer la realidad de las políticas sociales orientadas a la primera infancia y sus implementaciones.

Los Centros de Atención a la Infancia y la Familia (CAIF) integran el Sistema Nacional Integrado de Cuidados y conforman una red que atiende a 2600 niños en el departamento de Cerro Largo. Existen diecinueve Centros CAIF en el departamento, ubicados en diferentes áreas geográficas que comprenden Melo, la capital departamental, ciudades fronterizas y zonas rurales del departamento. La fundación de estos Centros data de diferentes fechas, y son 
gestionados por Organizaciones de la Sociedad Civil de diverso origen; todas de carácter honorario en su función de gestión.

Además de la propuesta propia de los Centros CAIF, los mismos constituyen un lugar de referencia para las comunidades, lo que posibilita la articulación de servicios estatales y de otros recursos. Es por ello que todos los Centros CAIF cuentan con equipos de trabajo integrados por maestras/os con especialización en Educación Inicial y/o experiencia comprobada de trabajo con la primera infancia, educadores/as, auxiliares de limpieza y educador/a alimentaria, cuyo número varía según el número de niños atendidos, y profesionales de las siguientes disciplinas: trabajadores sociales, psicólogos, psicomotricistas.

Es de señalar que tres de estos Centros CAIF se ubican en localidades de frontera. Esta condición de frontera los expone a temas como, familias binacionales, usos de servicios de salud a ambos lados de la línea nacional, necesidades especiales de educación en el desarrollo del lenguaje, informalidad laboral, etc.

\section{Metodología}

Nuestra aproximación metodológica a este trabajo de extensión parte de un abordaje transdisciplinario, aportando la mirada sociológica del territorio de frontera, los desafíos del trabajo social en ese contexto y el propósito de generar una experiencia educativa de capacitación para los operadores de los centros CAIF.

Consideramos que la implementación de una política social, más allá de la forma en que se concibe, diseña y expresa en sus documentos, implica un proceso de apropiación que conlleva interpretaciones y adaptaciones que se manifiestan en prácticas. Esas prácticas, a su vez, responden a disposiciones, hábitos y saberes (entendidos como conocimientos tácitos y explícitos) de los operadores involucrados, en un vínculo directo con la cultura propia de los contextos en los que se desarrollan. En ese proceso de implementación y sus múltiples niveles de gestión, se encuentran los desafíos que responden a la diversidad de cada territorio y de cada contexto social. La capacitación propuesta en este proyecto da cuenta de esa diversidad y aporta un análisis del contexto y herramientas para la gestión y puesta en práctica del plan de cada centro.

\section{Etapas}

Esta iniciativa surge de un encuentro interinstitucional, CEF - PLAN CAIF, a partir del cual se comienza un diálogo en el cual se indagan necesidades específicas. Como resultado se establecen las siguientes líneas de trabajo:

Familiarización con Plan CAIF Cerro Largo a partir de su documentación, de su información sistematizada y del contacto con sus autoridades.

- Exploración y relevamiento de información con el propósito de elaborar un perfil de las educadoras, dado que es la población objetivo de nuestro trabajo de extensión.

- Caracterización de la población atendida desde los CAIF de Cerro Largo, y las problemáticas que presenta vinculada a la situación de frontera. 
- Elaboración de una propuesta de capacitación que establece líneas generales de trabajo.

- Implementación de la capacitación

- Evaluación del proyecto

\section{La propuesta de capacitación}

La complejidad de la tarea, en particular la que desarrollan las educadoras, como aquellas que competen a todo el personal de cada uno de los Centros, requiere no solo un trabajo en equipo de gran fluidez, implica además la conjunción de saberes transdisciplinares que se puedan plasmar en prácticas efectivas. Esas son las prácticas que este proyecto de capacitación se propone fortalecer.

El dispositivo propuesto se estructura en una serie de Seminarios - Taller con contenidos específicos, manteniendo un hilo conductor a través de temas considerados transversales a todo el proceso formativo. Se trabajará con metodología de taller, concebida como un proceso de construcción de conocimiento colectivo, propiciando un espacio de formación desde una perspectiva participativa que considera a las personas sujetos activos de sus aprendizajes. En este sentido propone, entre otras dinámicas, la lectura orientada y el análisis de documentos de Plan CAIF, la reflexión a partir de las experiencias compartidas en el quehacer y el contacto cotidiano con el medio y la familiarización con herramientas de apoyo a la tarea de gestión y de aula. A tal fin, debe abordar temáticas como la comprensión de las implicancias del Plan CAIF como política social, la valoración del contexto de cada Centro en sus particularidades idiosincráticas y el desempeño de las educadoras, así como de todo el equipo del Centro en áreas claves como el trabajo colaborativo, el manejo de la comunicación organizacional, el contacto con las familias, y el manejo de situaciones complejas dentro del aula.

\section{Referencias}

ARIAS, A., GARCIA GODOY, B., MANES, R, Debates en torno a la construcción de institucionalidad. Aportes para la reconstrucción de lo público, UBA Sociales. Espacio editorial, 2014

MATUS, TERESA, et al. Innovar en calidad: construcción de un modelo de certificación de calidad para programas sociales1. Camino al Bicentenario Propuestas para Chile, 2008, p. 227-270.

Marco curricular para la atención y educación de niñas y niños uruguayos Desde el nacimiento a los seis años. Diciembre 2014. CCEIP/ UCC

ZAFFARONI, C., ALARCÓN, A. (2014) 25 años de Plan CAIF - Una mirada en profundidad a su recorrido programático e institucional. 